\title{
Empreendedorismo como escopo de diretrizes políticas da União Europeia no âmbito do ensino superior'
}

Rachel de Castro Almeida"

Miguel Chaves ${ }^{\text {III }}$

I- Este artigo foi realizado no âmbito do projeto "Percursos de inserção dos licenciados: relações objectivas e subjectivas com o trabalho" (PTDC/CSSOC/104744/2008), financiado por fundos nacionais portugueses, através da Fundação para a Ciência e Tecnologia, sediado no Centro de Estudos de Sociologia da Universidade Nova de Lisboa (CESNOVA) e do projeto "Ensino superior e inserção profissional: uma incursão pelas trajetórias e disposições de jovens empreendedores", realizado no quadro de uma bolsa de pós-doutorado da Capes (processo 4035-11/9).

II- Pontifícia Universidade Católica de Minas Gerais, Belo Horizonte, MG, Brasil. Contato: rachelalmeida@terra.com.br

III- Universidade de Lisboa, Lisboa, Portugal. Contato: miguel.chaves@fcsh.unl.pt

\section{Resumo}

Como resultado de orientações políticas propaladas pela União Europeia (UE), desde o início deste século, o ensino superior europeu, tem abarcado um novo desafio: potencializar o designado "espírito empreendedor". Os apelos ao empreendedorismo juvenil qualificado se estendem por todo o continente, adquirindo particular relevo nos países do sul, onde a crise europeia ecoa de forma mais aguda. A tendência das mais diversas instituições de ensino para adaptar seus procedimentos às diretrizes da UE consubstanciou-se na inclusão de novas disciplinas nos currículos, na criação de associações de estudantes ligadas ao empreendedorismo e no estabelecimento de estruturas administrativas e acadêmicas que fomentam a concepção de spin-off e a transferência de conhecimento. A despeito desses esforços disseminados, ainda não há uma tradição de avaliar e monitorar os resultados dessas iniciativas, não sendo assim possível conhecer e antecipar devidamente os seus resultados e impactos econômicos, nomeadamente no nível do emprego. Este artigo aponta três eixos analíticos centrais na observação desse novo vetor de transformação do ensino superior. Pretendemos desnaturalizar o conceito de empreendedorismo, evitando a armadilha da sua reificação; em seguida, realizaremos uma breve resenha acerca do desenvolvimento da noção de empreendedorismo no campo acadêmico; por fim, tencionamos documentar a relevância que as orientações empreendedoras têm assumido no desenho das políticas da UE, destacando a expressão que alcançaram no sistema educativo, com especial relevo para os seus patamares formativos mais elevados.

\section{Palavras-chave}

Ensino superior - Empreendedorismo - Políticas públicas Juventude - Inserção profissional. 


\section{Entrepreneurship as an aim of the European Union policy for higher education'}

Rachel de Castro Almeida"

Miguel Chaves"II

I- This paper was developed under the project "Graduates' transition to work trajectories - objective and subjective relations with work" (PTDC / CS- SOC / 104744/2008), funded by Portuguese national resources through the Foundation for Science and Technology, based in Centre for Sociological Studies of the New University of Lisbon (CESNOVA) and the project "Higher education and professional insertion: an incursion by the trajectories and provisions of young entrepreneurs", held as part of a postdoctoral grant from CAPES (process 4035-11/9).

Il-Pontifícia Universidade Católica de Minas Gerais, Belo Horizonte, MG, Brasil.

Contact: rachelalmeida@terra.com.br

III- Universidade de Lisboa, Lisboa,

Portugal.

Contact: miguel.chaves@fcsh.unl.pt

\section{Abstract}

As a result of the political guidance divulged by the European Union (EU), since the beginning of this century, higher education in Europe has included a new challenge: empowering the socalled "entrepreneur spirit". Encouragement of qualified youth entrepreneurship is widespread throughout the continent and has acquired special prominence in the Southern countries, where the European crisis has reverberated in more dramatic ways. The tendency among several educational institutions to adapt their procedures to the EU guidelines materialized in the inclusion of new disciplines in the curricula, in the creation of student associations linked to entrepreneurship and in the establishment of administrative and academic structures which foster the spin-off concept and knowledge transfer. Despite these efforts, there is still no tradition in assessing and monitoring the results of such initiatives, and, therefore, it is not possible to adequately know and anticipate their economic outcome and impact, namely on employment. This article indicates three major analytical lines in the observation of this new vector that is changing higher education. We intend to de-naturalize the concept of entrepreneurship by avoiding the trap of its reification; next, we shall conduct a brief review about how the notion of entrepreneurship developed in the academic field; finally, we aim to document the relevance that the entrepreneurial orientation has gained in the design of EU policies, highlighting how remarkable they have become in the educational system, especially for the highest educational degrees.

\section{Keywords}

Higher education - Entrepreneurship - Public policy - Youth Transition to work. 
Há algumas décadas, mas com especial ênfase a partir do final dos anos 1990, a União Europeia (UE) tornou-se uma instância crescentemente supranacional em matéria educativa, funcionando como fonte de elaboração de políticas no campo da educação e da formação, com implicações diretas nos sistemas de ensino dos Estados-membros. Assim, o campo do ensino superior europeu, após sofrer uma série de transformações como a expansão do número de estudantes e de instituições, uma formalização, com base em rankings, da hierarquia das escolas e um crescente processo de internacionalização (Programa Erasmus, Programa Leonardo da Vinci) -, vem sendo compelido a abraçar "novos desafios" que se encontram plasmados no uso e difusão de noções como "sociedade de aprendizagem", "sociedade do conhecimento", "sociedade da informação" e "aprendizagem ao longo da vida" (ANTUNES, 2005, p. 130). Essas noções estão se transformando em guias tanto para a interpretação da realidade quanto para a orientação das políticas institucionais ou ainda para a reconfiguração de conteúdos curriculares e pedagógicos.

0 termo empreendedorismo constitui mais uma dessas novas noções que vêm ganhando corpo nas estratégias da União Europeia e alicerçando ações e projetos desenvolvidos no âmbito dos Estados-membros, com o propósito de fomentar o "espírito empreendedor”. As orientações da UE preconizam que a formação empreendedora não fique adstrita ao ensino superior, mas que percorra todos os níveis de escolaridade, desde o ensino básico até a universidade, e que estabeleça fortes conexões com as políticas promotoras da aprendizagem ao longo da vida (COM, 2006). A esse propósito, vale acrescentar que a promoção do empreendedorismo tem se tornado uma espécie de nova função assumida pelo ensino superior, que se soma a todas as demais missões por este incorporadas, desde que, na primeira metade do século XIX, pelo pensamento dos irmãos Von Humbodlt, teve início um processo de profunda reforma da universidade europeia ${ }^{1}$.

No nosso ponto de vista, é preciso ultrapassar a barreira que dificulta a aproximação entre a sociologia e as temáticas associadas ao empreendedorismo, como se esse termo por si só expressasse um campo antinômico à sociologia.

$\mathrm{Na}$ atual conjuntura da esfera do trabalho, em que as incertezas estão muito mais presentes, em que se acentuam os constrangimentos para o ingresso no mercado de trabalho, os percursos de inserção profissional se diferenciam em função das estratégias de orientação no campo profissional, tanto em termos objetivos - dos recursos e das oportunidades - quanto em razão dos valores do trabalho almejados subjetivamente. Assim, conhecer os percursos dos jovens graduados que se tornaram empreendedores, a fim de compreender as suas motivações e aspirações profissionais, abre pistas para que as ações institucionais, desenvolvidas no âmbito das instituições de ensino superior, relacionadas à formação de jovens empreendedores sejam mais focalizadas e, consequentemente, tenham mais chance de êxito.

Os apelos ao empreendedorismo juvenil qualificado se estendem por toda a Europa, mas ganham particular relevo nos países do sul do continente, onde a crise europeia ecoa de forma mais aguda. Em Portugal, por exemplo, o empreendedorismo é apresentado por múltiplos agentes, dentre os quais se inclui o governo, como um desígnio absolutamente nuclear na recuperação da economia e na superação da crise. Esse contexto instiga a imaginação sociológica dos autores deste artigo, que desenvolvem atualmente um projeto de pesquisa acerca desse processo e que optam por compartilhar desde já três eixos analíticos considerados de capital importância para o desenvolvimento de pesquisas sociológicas acerca do tema do empreendedorismo. Esses eixos iluminam a necessidade de ampliar as

1- Para aprofundamento dessas questões, sugerimos ver: Santos e Almeida Filho (2008). 
pesquisas acadêmicas que visam a acompanhar e monitorar os avanços e os limites das propostas preconizadas pela $\mathrm{UE}^{2}$.

Primeiro, pretendemos desnaturalizar o conceito de empreendedorismo, evitando a armadilha da sua reificação, tornando saliente o modo como a ênfase nele colocada se encontra vinculada à difusão de princípios políticos e ideológicos (com implicações cognitivas) associados às transformações do capitalismo contemporâneo. Tais mudanças preconizam o afastamento do Estado da iniciativa econômica, ao mesmo tempo em que minimizam, quer no plano legal - isto é, na legislação laboral - quer no plano simbólico, as expectativas de segurança contratual por parte dos trabalhadores. Ou seja, essas alterações rompem estruturas que foram apanágio do modelo fordista (AMIN, 1994; KUMAR, 1997; LASH; URRY, 1987). Em seguida, realizaremos uma breve resenha do surgimento e desenvolvimento da noção de empreendedorismo no campo acadêmico, salientando o peso crescente que o tema vem adquirindo no contexto científico. Em um terceiro momento, almejamos documentar a relevância que as orientações empreendedoras têm assumido no desenho das políticas da UE, destacando a expressão que alcançaram no sistema de ensino superior europeu, assumindo um protagonismo sem precedentes.

Embora essas iniciativas não estejam presentes de forma acentuada e estruturada em termos de orientação política na realidade brasileira contemporânea, a formação empreendedora, se ainda não é, tende a ser um desafio transversal a atingir indiscriminadamente diversos países nos mais distintos cenários econômicos. Esses três eixos analíticos ultrapassam o contexto europeu e iluminam a observação desta dinâmica.

\footnotetext{
2- Os autores se dedicam ao projeto de pesquisa "Ensino superior e inserção profissional: uma incursão pelas trajetórias e disposições de jovens empreendedores", que tem como principal escopo analisar em que medida esse novo discurso e as políticas que 0 acompanham deram de fato azo à formação de disposições e orientações empreendedoras junto aos diplomados do ensino superior.
}

\section{Empreendedorismo: polissemia} terminológica e orientações ideológicas

Como já alertara Bourdieu (1998), as esferas da religião e da política são os domínios que tiram maior partido da polissemia inerente à ubiquidade social da língua. Nas sociedades complexas contemporâneas, as palavras não possuem um sentido neutro; antes são investidas de sentidos sociais pelos atores que as mobilizam. Em alguns casos, assumem significados diferenciados para os emissores e receptores que ocupam posições diferentes no espaço social e que, por essa razão, desenvolvem e transportam intenções e interesses distintos ou mesmo antagônicos.

0 termo empreendedorismo se revela um bom exemplo dessa polissemia. É preciso reconhecer que tal noção - em particular, o seu sentido, urgência e necessidade - está sendo naturalizada e incorporada a muitos discursos como autoevidente. Se, em uma acepção minimal, com o termo empreendedorismo se pretende designar apenas a propensão para a criação de empresas, em outra, cada vez mais frequente, o termo surge associado ao engrandecimento das qualidades de determinados tipos de ações e de indivíduos, virtudes que procuraremos identificar em seguida, mas que os distinguem face aos demais e que lhes conferem o reconhecimento de estarem alinhados com as lógicas e exigências do seu próprio tempo. A naturalização e a reificação do termo encontram-se, hoje em dia, associadas a formas de violência simbólica que urge deslindar, independentemente da relevância que possam ter para as finalidades que se pretende atingir e da posição que o próprio pesquisador possa assumir em relação à necessidade ou justeza dos fins preconizados.

0 que está em causa, no fundo, é a difusão, juntamente com a noção de empreendedorismo, de um conjunto de axiomas que ultrapassam os limites da própria criação de empresas para passarem a assumir o estatuto de virtudes públicas. Merecem assim, hoje em dia, o epíteto 
de empreendedores os indivíduos que "não se conformam, que têm iniciativa própria e não ficam esperando nem pelo Estado de bem-estar, nem por ações coletivas" (ROESE, 2011). As qualidades do empreendedor são exaltadas como virtudes, manipuladas de modo essencialmente maniqueísta, correspondendo "à capacidade de trabalho em oposição à preguiça; à iniciativa em oposição à passividade; à criatividade em oposição à mediocridade; à diferenciação em oposição ao padrão” (ROESE, 2011, p. 2). 0 sujeito empreendedor seria, portanto:

(...) o herói emblemático que ousa desbravar caminhos novos, que incorpora o risco em suas ações, que quebra regras e que reconhece oportunidades onde ninguém mais as consegue perceber. (COSTA, 2010, p. 13).

Assim, torna-se evidente o modo como o fomento do espírito empreendedor estabelece estreitas associações com o espírito que subjaz ao capitalismo contemporâneo, nos termos em que L. Boltanski e È. Chiappello (2002) o enunciam e aprofundam no novo clássico Le nouvel esprit du capitalisme. 0 sujeito empreendedor é aquele que é capaz de criar o próprio emprego, mas também de se manter empregável, de gerir seus próprios recursos, de controlar o seu tempo de trabalho, sendo para tal indispensável conectar-se a redes e envolver-se em um "mundo de projetos". Trata-se, no fundo, do trabalhador ideal para o atual capitalismo, que preconiza a necessidade de flexibilidade de mão de obra, de trabalhadores em part time, de trabalho terceirizado ou independente (ANTUNES, 2007). Os sujeitos que vivenciam esse "mundo de projetos" são concebidos como entidades que deverão se mostrar sempre aptas a conectar-se com outros, a estabelecer relações e a desenvolver projetos em equipe. São engrandecidos aqueles que demonstram estar na posse de tais competências, as quais lhes permitem integrar-se nesse novo "regime de ação", isto é, que demonstram capacidade de comunicação e de persuasão, que conseguem inspirar confiança, que se ajustam aos outros, que se adaptam às situações, que se encontram em mudança permanente. 0 conjunto dessas capacidades pressupõe a renúncia à estabilidade, ao enraizamento às pessoas, às coisas, às organizações, a determinadas categorias e identidades profissionais pré-definidas (SENNETT, 1999; DUBAR, 2006), ou seja, a tudo o que envolva comprometimentos de longo prazo e que impeça a disponibilidade para se ensaiar novos projetos e novas conexões. Ora, se refletirmos bem, esses dois elementos - projetos e conexões - estão estreitamente inter-relacionados, pois se, por um lado, os projetos promovem uma desejável expansão das conexões e das próprias redes, estas últimas são, por seu turno, imprescindíveis ao desenvolvimento e à necessária multiplicação dos projetos. Esses princípios são válidos quer para o empreendedor, criador de empresas, quer para o trabalhador assalariado, enquanto portador do espírito empreendedor. Embora não absoluta, a homologia entre essas duas figuras surge explicitada em várias obras orientadas para a formação do "homem de negócios", como, por exemplo, num texto em que R. Heller reflete sobre T. Peters: "Torne qualquer pessoa numa pessoa de negócios. Desenvolva em todos os empregados 'a mentalidade de um concessionário independente” (2000, p. 22). Ou ainda em várias frases inclusas em revistas de administração, que foram sujeitas a um extenso trabalho de análise de conteúdo por T. Lapa (2006, p. 13):

Somos um produto que precisa, para ser rentável, de ser bem vendido. Somos uma empresa unipessoal. Criada, pensada e gerida por nós próprios.

Os padrões simbólico-cognitivos (LAPA, 2006) que acabamos de assinalar constituem, no fundo, uma verdadeira cultura do mundo do trabalho contemporâneo, que se alastra e percorre vastas áreas do cosmos social, tangendo inclusive os indivíduos que não experimentam 
situações de flexibilidade, nomeadamente os assalariados que detêm vínculos contratuais mais seguros e estáveis.

À semelhança de outros padrões culturais, a cultura do mundo do trabalho contemporâneo não adquire sempre o mesmo grau de sistematização e de codificação. Assume a sua forma mais sofisticada e coerente nos manuais de gestão, mas está também presente, em formatos menos elaborados, no pensamento e nos discursos do senso comum, ganhando difusão a partir de múltiplos suportes midiáticos. No entanto, seja qual for o seu suporte, ela opera, sobretudo, por meio de princípios e critérios com base nos quais se estipula o modo "como se deve ser", “como se deve estar", "como se deve agir" no universo laboral e no sistema econômico hodierno. Ao se encontrarem imersos nesse caldo cultural, os indivíduos que, no momento presente, procuram fazer parte da estrutura produtiva sentirão, pelo menos em parte, que apenas desenvolvendo uma postura empreendedora será possível manterem-se inseridos e valorizarem-se no plano simbólico, tanto por parte dos outros quanto de si mesmos.

Numa época em transição, um dos maiores desafios do pensamento crítico é justamente perceber as mudanças sociais, políticas e econômicas profundas, uma vez que os conceitos ou categorias utilizados para descrever e analisar a complexa realidade, muitas vezes, não conseguem dar conta das dimensões envolvidas nesses processos (SOUZA, 2010). Com efeito, essas categorias são apresentadas de forma reificada, como se descrevessem a realidade, quando, na verdade, constituem-na. Já Berger e Luckmann (1966) apontavam que o ato de descrever a realidade "tal como ela é" (ou seja, explicar o "modo como as coisas funcionam") constitui um dos componentes do processo de legitimação. Descrever e estabelecer normas são, nessa acepção de legitimação (enquanto objetivação de "segunda ordem”), dois exercícios que se imiscuem.

Procuramos chamar a atenção para o fato de que, mesmo que a análise da temática empreendedora não vise a condenar a utilização do termo ou as dinâmicas que subjazem a ele, não pode deixar de ter presente o propósito de desmontar o discurso dominante ao invés de o “comprar ingenuamente" (SOUZA, 2010). Tratase, no fundo, de seguir as recomendações de Bourdieu (1998, p. 19) ao afirmar que "a ciência social deve autonomizar-se da língua, da sua lógica específica, das suas regras próprias de funcionamento", no sentido de produzir o seu próprio objeto de análise, objeto do qual fazem parte os operadores linguísticos constitutivos da realidade e as operações e interesses que estão na base da sua criação e difusão.

Ensaiaremos, a seguir, um conciso excurso sobre os vários conteúdos que 0 conceito de empreendedorismo tem assumido no campo científico.

\section{A noção de empreendedorismo no campo acadêmico}

Um breve périplo pelas acepções de empreendedorismo presentes em contexto científico revela que, como qualquer outro conceito, tanto a gênese quanto a evolução encontram-se permeadas por especificidades históricas de índole social, econômica e política, além de estarem marcadas pelas várias perspectivas disciplinares que subjazem a elas. As noções de empreendedorismo promovidas por economistas, psicólogos, sociólogos e administradores, como seria previsível, tendem a ser distintas. Os desenvolvimentos das últimas décadas são densos, diversificados e, novamente, polissêmicos. De forma sucinta, mostraremos o modo como esse tema é alvo de definições ora convergentes ora divergentes.

Joseph Schumpeter (1961), que influenciou em muito o pensamento científico em torno do tema, atribuiu ao empreendedor o papel de manter a estrutura capitalista por meio da destruição criativa, propalando, em consequência, a sua importância enquanto força vital para a economia (AUDRETSCH, 2003; LÓPEZRUIZ, 2004; ASSUNÇÃO, 2008). A destruição criativa seria o resultado do próprio processo 
de desenvolvimento econômico (e seus ciclos), e decorreria especialmente da inovação promovida pela:

(a) introdução de um novo bem ou de um bem já existente com nova característica; (b) introdução de um novo método de produção; (c) abertura de um novo mercado; (d) descoberta de novas fontes de suprimento; e (e) desenvolvimento de novas formas de organização. (COSTA, 2010, p. 26).

Outro aspecto influente da obra de Schumpeter (1961) é o fato de este definir o empreendedor a partir de atitudes, de modos de agir, de um comportamento ditado por uma disposição interior. Os empreendedores são, assim, aqueles indivíduos que têm iniciativa, uma boa dose de intuição, força de vontade e liberdade mental, aversão à rotina, certa autoridade e capacidade de previsão do futuro. Em suas palavras:

(...) não são só aqueles homens de negócios "independentes", de uma economia mercantil, que são geralmente assim designados, como também todos os que, realmente, preenchem aquela função que definimos; ainda que, como está sendo a regra geral, sejam empregados "dependentes" de uma companhia, como gerentes (...). (SCHUMPETER, 1961, p. 101-102).

A incursão que Schumpeter (1961) levou a cabo em Teoria do desenvolvimento econômico, procurando desbravar a estrutura motivacional do empreendedor, tornou-se objeto de interesse por parte dos psicólogos engajados na corrente behaviorista, dentre os quais se destaca o protagonismo de David McClelland (1961). No âmbito dessa corrente, criaram-se testes com o objetivo de se mensurar o potencial empreendedor de cada indivíduo, uma vez que os sujeitos passaram a ser considerados os agentes responsáveis pelo essencial da tomada de decisões e de iniciativas empreendedoras.
McClelland aponta, por exemplo, que a "necessidade de realização" (achivementneed) é a principal força motriz da ação empreendedora, acrescentando que essa necessidade é internalizada na fase de socialização primária, em função dos valores transmitidos pela família. 0 argumento de que essa necessidade é originada na socialização primária foi rebatido por estudos posteriores, designadamente por Inkeles e Smith (CABRAL, 1996), que demonstraram que os coeficientes de correlação entre a orientação da realização pessoal e a socialização primária e secundária são praticamente idênticos. 0 trabalho de McClelland foi, no entanto, essencial para o avançar da pesquisa. 0 interesse em confirmar ou refutar a hipótese desse autor esteve na base do surgimento de outras pesquisas que assumiram a preocupação de identificar as características comportamentais que definem os empresários, distinguindo-os dos não-empresários. As principais respostas assinalaram a presença de dimensões como o "desejo do risco" e a "orientação a partir de determinados valores" (GARTNER, 1989).

É certo que a abordagem comportamental assumiu também outras direções, defendendo-se, em alguns casos, que as características de personalidade dos empreendedores eram acessórias, quando comparadas com a importância das ações por eles efetivamente desempenhadas. As pesquisas sobre os empresários deviam, portanto, concentrar-se naquilo que os empresários fazem e não tanto naquilo que eles são. Estabelecendo-se uma analogia com os jogadores de futebol, dir-se-ia que, embora fosse possível descrever as diversas caraterísticas de cada um desses atletas, o que interessava não era tanto enumerar e descrever os seus traços pessoais intrínsecos, mas sim analisar aquilo que eles conseguem, de fato, fazer: driblar, correr em alta velocidade, agarrar no gol e realizar um passe perfeito etc. (GARTNER, 1989).

Foi ainda por via da perspectiva behaviorista que ganharam asas alguns dos 
mais importantes estudos dedicados a averiguar o potencial empreendedor dos indivíduos. Nesse âmbito, deve destacar-se o projeto Global Entrepreneurship Monitor (GEM), considerado o maior estudo em andamento sobre as dinâmicas empreendedoras no mundo. Desenvolvido desde 1999, com base em uma parceria entre a London Business School (Reino Unido) e o Babson College (EUA), essa pesquisa vem realizando análises comparadas entre diversos países, no âmbito da referida temática. 0 empreendedorismo é abordado como:

(...) qualquer tentativa de criação de um novo negócio ou nova iniciativa, tal como emprego próprio, uma nova organização empresarial ou a expansão de um negócio existente, por parte de um indivíduo, de uma equipa de indivíduos, ou de negócios estabelecidos. (GEM, 2010, p. 4).

0 foco central dessa equipe de pesquisadores passa por mensurar o nível de atividades empreendedoras em diferentes países, procurando analisar as condições estruturais que promovem ou dificultam o lançamento dessas iniciativas. 0 modelo de análise envolve cinco variáveis: as condições estruturais de cada país; a atitude empreendedora (a predisposição dos indivíduos ao risco e à percepção de novas oportunidades); a atividade empreendedora (empreendimentos iniciados); a aspiração empreendedora (qualidade das oportunidades de negócio em termos de inovação, internacionalização); e o crescimento econômico nacional.

Por fim, e dada a natureza do estudo que pretendemos desenvolver, importa destacar ainda um conjunto de pesquisas centradas na população jovem universitária, que associa as motivações empreendedoras às competências psicológicas, às aptidões sociais e às habilidades de gestão (SANTOS; CAETANO; CURRAL, 2010; TEIXEIRA, 2008). Esses pesquisadores enfatizam a importância de se compreender o potencial empreendedor existente entre os estudantes universitários dos mais variados cursos, e têm também em comum o fato de procurarem identificar as intenções e não apenas as ações concretas de empreendedorismo. Apoiados na vertente behaviorista, em busca de uma "psicologia do empreendedorismo", tais trabalhos já apontam a preocupação com as ações dispersas e isoladas desenvolvidas pelas instituições de ensino superior portuguesas visando às políticas preconizadas pela UE (CAETANO; SANTOS; COSTA, 2012).

\section{Empreendedorismo enquanto diretriz política}

As principais justificativas mobilizadas pela União Europeia para a difusão da formação empreendedora assentavam na preocupação com a preservação do Estado do bem-estar social, vigente em grande parte dos países europeus e considerado um modelo social exitoso. Sustentava-se que esse modelo estava a sofrer importantes riscos e reveses diante da conjuntura política e econômica mundial. De fato, a União Europeia ainda não conseguiu diminuir o desnível do PIB per capita em relação aos Estados Unidos e as perspectivas de futuro assinalam que tenderá a reduzir o percentual de participação na produção mundial, especialmente com a recuperação das economias asiáticas emergentes (COM, 2004a; COM, 2006). A recente crise não veio senão fragilizar ainda mais a posição europeia no cenário mundial. Assim, o progresso e desenvolvimento sustentável do continente, com vista à preservação da sua posição no sistema econômico mundial, depende, segundo a própria UE, da inovação e da competitividade. Sem esses dois atributos, proclama-se, não será possível relançar a economia.

As dinâmicas de contração demográfıca documentadas e projetadas acirram ainda mais o apelo ao desenvolvimento do espírito empreendedor. Por um lado, estima-se que um terço dos empresários da UE, especialmente os responsáveis por empresas familiares, 
aposentar-se-ão nos próximos anos, afetando 2,4 milhões de empregos por ano. Por outro, o grupo etário mais ativo na criação de empresas - os jovens entre 25 e 34 anos sofrerá uma redução drástica nas próximas décadas, em função do declínio da natalidade (COM, 2004a). Esse contexto interno e externo promove um ambiente em que a dinamização do proclamado espírito empreendedor ganha foros de meta supranacional, compartilhada pelos diversos países, sendo as instituições de ensino consideradas um canal privilegiado para a sua difusão.

Neste terceiro bloco, pretendemos diagnosticar o modo como o termo empreendedorismo é empregado pela UE nas suas diretrizes políticas, utilizando para o efeito dois tipos de documentos: a) os textos programáticos da Comissão Europeia; e b) os relatórios de avaliação gerados por essa mesma entidade supostamente independente, mandatada para a defesa dos interesses da UE no seu conjunto. É sobretudo a partir desses dois documentos que se forjam e irradiam as orientações pró-empreendedoras para o interior das instituições de ensino superior, orientações essas que, voltamos a sublinhar, têm contaminado todo o sistema de ensino, nos seus diversos patamares.

No essencial, ventila-se que a educação empreendedora, até o momento bastante circunscrita aos cursos de administração e economia, deverá expandir-se para além desses domínios científicos, passando a integrar a matriz curricular de todos os cursos universitários. Todas as áreas deverão procurar difundir, idealmente, junto a seus alunos, uma formação vocacionada para a criação e gestão de empresas. Em simultâneo, sustenta-se que as instituições de ensino devem: estabelecer incubadoras de empresas e, sempre que possível, parques científicos; promover concursos destinados a premiar planos de negócios; disseminar a utilização de estudos de caso e outros métodos de ensino interativos; incentivar a transferência da inovação e do conhecimento gerado no ensino superior (spin-offs e start-ups), com destaque para as novas tecnologias. Além disso, recomenda-se que os próprios cursos de administração procurem, de forma mais enfática, desenvolver uma pedagogia diretamente orientada para a criação de empresas, quer dizer, um ensino tanto focalizado na gestão da fase de crescimento das pequenas e médias empresas quanto centrado no fomento e promoção da inovação permanente (COM, 2006).

De um ponto de vista pedagógico, o desenvolvimento do espírito empreendedor deve estar apoiado na aquisição de competências de quatro tipos: pessoais, sociais, relativas à gestão e empresariais. As competências pessoais consubstanciam-se em autoconfiança, motivação, desenvolvimento de pensamento crítico e autonomia; as sociais, em capacidade de cooperar, de criar redes, de trabalhar de forma reticular e de assumir novos papéis; as competências associadas à gestão, na resolução de problemas, no planejamento, na tomada de decisões, na comunicação e na predisposição para a assunção de responsabilidades. No que concerne às competências empresariais, os estudantes deverão desenvolver iniciativa, criatividade, atitudes proativas e a disposição para enfrentar o risco e implementar novas ideias (COM, 2004b).

Basta um olhar atento para que se torne perceptivel que as competências fundamentais para a criação e o desenvolvimento de empresas são em tudo similares às consideradas necessárias para se aumentar a satisfação pessoal, potencializar a inclusão social e a cidadania ativa e expandir a aprendizagem ao longo da vida.

0 que se preconiza, portanto, é uma concepção maximalista de competências pró-empreendedoras, tal como assinalam Lopéz Ruiz (2004) e Colbari (2007) quando referem que as competências atreladas ao empreendedorismo se alastram para além da figura do empreendedor enquanto empresário, passando a se materializar, no âmbito corporativo, nas relações de trabalho contemporâneas, vinculando os 
trabalhadores assalariados a um complexo de deveres dos quais se presume depender a sua manutenção no mercado de trabalho. Em larga medida, essas ideias estão presentes na própria noção de espírito empreendedor emanada da Comissão Europeia. Para essa entidade, nuclear na orgânica da UE, o espírito empreendedor deve ser definido como:

[...] a capacidade dos indivíduos de converter ideias em actos. Compreende a criatividade, a inovação e a assunção de riscos e, bem assim, a capacidade de planear e gerir projectos com vista a alcançar objetivos. Esta competência é útil a todos na vida de todos os dias, em casa e na sociedade, aos trabalhadores porque os torna conscientes do contexto do seu trabalho e aptos a aproveitar oportunidades, aos empresários porque serve de base para o estabelecimento de uma actividade social ou comercial. (COM, 2006, p. 4).

Mapeados os princípios essenciais do empreendedorismo, observemos agora brevemente a forma como esses se consubstanciam no interior das próprias instituições de ensino. Em relação a esse ponto, constata-se que as universidades europeias têm trilhado um caminho comum: a criação de gabinetes de promoção das atividades empreendedoras; o desenvolvimento de atividades de formação com durações diversas acerca da matéria; o estabelecimento de estruturas administrativas e acadêmicas que fomentam a criação de empresas spin-off e a transferência de conhecimento e o estímulo à criação de clubes de empreendedorismo, erigidos pelos próprios estudantes (ABRANJA, 2009; COSTA, 2011; MOREIRA, 2009; NAIA, 2009; UNIVERSIDADE DE LISBOA, 2011).

Por sua vez, o grau de empenho das escolas do ensino superior na assimilação das orientações pró-empreendedoras tem sido alvo de avaliação por parte das entidades supranacionais da UE, apreciação que se encontra vertida em dois importantes relatórios emanados da Comissão Europeia: Survey of Entrepreneurship Education in Higher Education in Europe e Contribuir para a Criação de uma Cultura Empresarial: um guia de boas práticas para a promoção de atitudes e competências empresariais através da educação.

Destacamos, em primeiro lugar, o relatório Survey of Entrepreneurship Education in Higher Education in Europe. Esse documento, desenvolvido pela Comissão Europeia (2008), teve por missão: eleger as melhores práticas desenvolvidas pelas instituições de ensino; promover a criação de um ranking de instituições, no qual ganharam expressão os quesitos associados ao ensino do empreendedorismo; e, finalmente, identificar as principais dificuldades enfrentadas pelas instituições de ensino para colocarem em prática as formações orientadas para as atividades empreendedoras. Ao propor a criação de um ranking das instituições de ensino superior no domínio do empreendedorismo, os pesquisadores envolvidos elaboraram um índice de desempenho composto por três indicadores: alunos empreendedores por aprendizagem; alunos empreendedores por experiência prática; e transferência de conhecimento. Do grupo de 25 países que, à época, constituíam a UE, França, Alemanha e Reino Unido ocuparam o primeiro lugar no domínio do desempenho, ao passo que, na área das condições infraestruturais, foram de novo a França e o Reino Unido a liderar o ranking, mas, agora, acompanhados da Hungria. Portugal, país onde, como se tornará nítido no bloco seguinte, incide o estudo que motiva o presente artigo, surge em $12^{\circ}$ lugar no item desempenho, ascendendo a sexto lugar no domínio das infraestruturas.

0 relatório Contribuir para a Criação de uma Cultura Empresarial: um guia de boas práticas para a promoção de atitudes e competências empresariais através da educação destaca-se por inventariar as principais boas práticas desenvolvidas pelas instituições de ensino superior europeias, 
segundo as observações do Procedimento Best $^{3}$. Esse documento destacou as estratégias desenvolvidas pela Gründerplattform der Wiener Universitäten (Áustria), pela Escola Empresarial Norueguesa (Noruega), pelo Dundalk Institute of Technology (Irlanda), pelo Programa Temporary Entrepreneurial Position (TOP) da University of Twente (Países Baixos), e pelo Programa Science Enterprise Challenge (Reino Unido).

É frutífero, para que se entenda o tipo de orientações privilegiadas pela EU, sumarizar cada uma das "boas práticas".

$\mathrm{Na}$ Áustria, todos os estudantes da fase final dos cursos de graduação nas mais distintas áreas de formação participaram de um concurso cujo objetivo era desenvolver um plano de negócios, trabalhando em equipes multidisciplinares. 0 exemplo norueguês (dirigido apenas aos estudantes de ciências e de engenharias) iniciava-se com um curso preparatório sobre gestão, a que se sucedia um prova de seleção. Os estudantes eleitos realizavam então um trimestre de estágio em empresas sediadas no estrangeiro (São Francisco, Boston, Singapura, Xangai). Após a formação, desenhavam um projeto a aplicar no ambiente empresarial norueguês. $\mathrm{Na}$ Irlanda, os alunos do Dundalk Institute of Technology que frequentavam qualquer curso de graduação ou pós-graduação podiam incluir em sua grade módulos de formação empreendedora que abarcavam conhecimentos teóricos e aplicações práticas. Nos Países Baixos, por meio do programa Temporary Entrepreneurial Position (TOP), os estudantes de nível superior que assim o desejassem podiam realizar um curso específico sobre empreendedorismo, desenvolver um plano de negócios, iniciar atividades empresariais em uma incubadora sediada na universidade,

3- 0 procedimento Best é um método aberto de coordenação em matéria de melhoria do enquadramento empresarial. É a resposta da Comissão Europeia ao apelo do Conselho Europeu de Lisboa de 23 e 24 de março de 2000, no sentido de disseminar as principais práticas e de criar sinergias entre os diferentes processos orientados para a promoção da cultura empreendedora. Para mais informações, ver: <http:// europa.eu/legislation_summaries/enterprise/business_environment/ n26113_pt.htm>. participar de equipes de investigação na área do produto ou do negócio gerados e, finalmente, tornar-se elegíveis para a obtenção de uma diversidade de apoios talhados à medida do seu projeto. A experiência exitosa identificada no Reino Unido resultava, por seu turno, de uma rede de centros de excelência das universidades britânicas, especializados no ensino e na prática de atividades comerciais e empresariais no campo da ciência e da tecnologia (COMISSÃO EUROPEIA, 2004).

Passados menos de dez anos do início de sua difusão, iniciativas desse tipo, com destaque para as promovidas nos exemplos austríaco, norueguês e irlandês, vulgarizaram-se, sendo aplicadas por múltiplas escolas europeias do ensino superior.

Finalmente, o relatório Survey of Entrepreneurship Education in Higher Education in Europe identificava as principais dificuldades com que as instituições do ensino superior se confrontavam no ensino do empreendedorismo, a saber: a) o restrito número de educadores com formação na área; b) o reduzido tempo do corpo docente para se dedicar ao ensino dessas matérias; c) a indisponibilidade de recursos; d) a falta de infraestrutura; e) as dificuldades de alteração e de adaptação curricular; e f) o fato do empreendedorismo ser entendido como uma atividade que perverte a missão de produção e difusão de conhecimento que subjaz à universidade (instrumentalizando-a em termos mercantis), fato esse que desencadeia reações de antagonismo no interior de diversos departamentos. Como se afirma nesse documento,

(...) not all departments were convinced that it was a good idea to engage in entrepreneurship education as they were afraid that the institution would be too commercial and that it would loose academic values. (NIRAS Consultants, FORA, ECON Pöyry, 2008, p. 202).

A esses aspectos, consideramos fundamental acrescentar, não nos reportando, porém, 
aos relatórios supracitados, que a ênfase no empreendedorismo é conotada por muitos agentes do espaço universitário europeu como um instrumento ideológico que integra a "agenda neoliberal”, suscitando, também por essa via, resistências, neste caso, de âmbito político.

\section{Efeitos de um projeto político:}

futuros passos de um estudo em aberto

Não é por acaso que o termo empreendedorismo emerge com tanta força no discurso político em um momento de crise. Diante do atual acirramento dos entraves na esfera do trabalho, associados à crise do emprego e flexibilização do trabalho, essa abordagem de cariz político e ideológico é apresentada como alternativa para o crescimento sustentável europeu e, consequentemente, para o processo de inserção profissional dos egressos do ensino superior.

Os próprios dados do Global Entrepreneurship Monitor (GEM, 2010) revelam que uma das motivações para iniciar uma atividade empreendedora é o fator necessidade. 0 empreendedorismo por necessidade é identificado nas situações em que as condições de vida dos indivíduos estão longe daquelas consideradas pelos próprios como ideais, em que há falta de oportunidades de emprego formal e necessidade de aumentar os rendimentos mensais. Como a raiz da necessidade está muito atrelada às dinâmicas de absorção e retração do mercado de trabalho, em momentos de crise, o próprio mercado inicialmente impele os novos negócios.

Nesse cenário, parece haver uma corrida contra o tempo, em que a aprendizagem ao longo da vida emerge associada à formação baseada no desenvolvimento de competências profissionais e à formação empreendedora, orientada tanto para a criação de autoemprego quanto para o desenvolvimento de iniciativas inovadoras. As instituições de ensino superior são confrontadas com um novo desafio para o qual não estavam preparadas, especialmente no quesito recursos humanos. Além disso, enfrentam outros limites, como o acesso aos recursos para financiar os novos negócios ou produtos, as dificuldades geradas pelas alterações curriculares, com a inclusão das disciplinas na área, e as próprias diferenças internas que, algumas vezes, colocam em causa as diretrizes da UE, uma vez que associam essa concepção de disseminação de práticas educativas voltadas ao desenvolvimento do espírito empreendedor aos princípios neoliberais.

Os estudos de caso confirmam que as ações institucionais convergem em um sentido único: a implantação de gabinetes de promoção ao empreendedorismo, a inclusão de novas disciplinas optativas nos currículos dos cursos das mais diversas áreas, a ampliação da oferta de cursos de verão e de curta duração e a disseminação dos concursos de planos de negócios. Entretanto, nota-se que há em comum o fato de a abrangência ainda ser bastante restrita e de não haver um processo instituído de avaliação ou monitoramento dos resultados.

Sintetizando, podemos afirmar que se encontra hoje em dia erigido, no sistema do ensino superior europeu - em estreita sintonia com as transformações em curso no capitalismo global e procurando, em simultâneo, responder às questões que se colocam à Europa nesse mesmo contexto -, um dispositivo de fomento do empreendedorismo, sustentado, por um lado, numa apreciável logística e, por outro, na transmissão de competências e de injunções ideológicas. Torna-se fundamental apurar quais tipos de impacto todo esse complexo tem no conjunto da população que explicitamente pretende atingir: os estudantes e, em particular, os graduados do ensino superior.

\section{Referências}

ABRANJA, Helena Rita Gonçalves Marinho. Mobilidade e empreendedorismo no ensino superior: 0 caso das ciências sociais. 2009. Tese (Mestrado em sociologia) - Universidade do Minho, Braga, 2009. 
AMIN, Ash (Ed). Post-fordism: a reader. Oxford: Blackwell, 1994.

ANTUNES, Fátima. Globalização e europeização das políticas educativas: percursos, processos e metamorfoses. Sociologia, Problemas e Práticas, Lisboa, n. 47, p. 125-143, jan. 2005.

ANTUNES, Ricardo. Adeus ao trabalho? Ensaio sobre as metamorfoses e a centralidade do mundo do trabalho. São Paulo: Cortez; Campinas: Edunicamp, 2007.

ASSUNÇ̃̃O, Fátima. Do emprego à empresa?: uma reflexão sobre o auto-emprego, a pequena propriedade e o empreendedorismo. In: CONGRESSO PORTUGUÊS DE SOCIOLOGIA, 6., 2008, Lisboa. Mundos sociais: saberes e prácticas. Lisboa: Associação Portuguesa de Sociologia, 2008. p. 345.

AUDRETSCH, David B. Entrepreneurship: a survey of the literature. Brussels: European Communities, 2003.

BERGER, Peter; LUCKMANN, Thomas. A construção social da realidade: tratado de sociologia do conhecimento. Lisboa: Dinalivro, 2004. Primeira edição 1966.

BOLTANSKI, LuC; CHIAPELLO, Éve. El nuevo espíritu del capitalismo. Madrid: Akal, 2002.

BOURDIEU, Pierre. 0 que falar quer dizer: a economia das trocas linguísticas. Lisboa: Difel, 1998.

CABRAL, Manuel Villaverde. Sociedade e desenvolvimento econômico. In: FERREIRA, J. M. Carvalho et al. (Orgs.). Entre a economia e a sociologia. Oeiras: Celta, 1996.

CAETANO, António; SANTOS, Susana Correia; COSTA, Silvia Fernandes. Psicologia do empreendedorismo: processos, oportunidades e competências. Lisboa: Mundos Sociais, 2012.

COLBARI, Antônia de L. A retórica do empreendedorismo e a formação para o trabalho na sociedade brasileira. SINAIS, Vitória, v. 1, n. 1, p.75-111, abr. 2007.

COM - Comissão das Comunidades Europeias. Comunicação da Comissão ao Conselho e ao Parlamento Europeu, ao Comité Económico e Social Europeu e ao Comité das Regiões sob o título aplicar o programa comunitário de Lisboa: promover o espírito empreendedor através do ensino e da aprendizagem. COM, Bruxelas, 33 final, 13 fev. 2006.

COM - Comissão das Comunidades Europeias. Comunicação da Comissão ao Conselho, ao Parlamento Europeu, ao Comité Económico e Social Europeu e ao Comité das Regiões. Plano de Acção: a agenda europeia para 0 espírito empresarial. CoM, Bruxelas, Comissão das Comunidades Europeias, 2004a.

COM - Comissão das Comunidades Europeias. Comunicação da Comissão "Educação e formação para 2010: a urgência das reformas necessárias para o sucesso da estratégia de Lisboa". Projecto de relatório intercalar conjunto do Conselho e da Comissão sobre a realização do programa de trabalho relativo ao seguimento dos objectivos dos sistemas de ensino e formação na Europa. COM, Bruxelas, Comissão das Comunidades Europeias, 2004b.

COMISSÃO EUROPEIA. Contribuir para a criação de uma cultura empresarial: um guia de boas práticas para a promoção de atitudes e competências empresariais através da educação. Luxemburgo: Serviço das Publicações Oficiais das Comunidades Europeias, 2004

COSTA, Alessandra de Sá Mello da. Convergências, divergências e silêncios: 0 discurso contemporâneo sobre 0 empreendedorismo nas empresas júniores e na mídia de negócios. 2011. 285 f. Tese (Doutorado em Administração) - Fundação Getúlio Vargas, Escola Brasileira de Administração Pública e de Empresas, Rio de Janeiro, 2011.

DUBAR, Claude. A crise das identidades: a interpretação de uma mutação. Porto: Afrontamento, 2006.

GARTNER, William B. Who is an entrepreneur? Is the wrong question. Entrepreneurship Theory and Practice, v. 13, p. 47-68, verão, 1989.

Global Entrepreneurship Monitor - GEM. Portugal 2010: estudo sobre 0 empreendedorismo. Disponível em: <http://www. gemconsortium.org/docs/download/2271>. Acesso em: 2013.

HELLER, Robert. Tom Peters: autor de bestsellers e profeta da revolução da gestão. Porto: Civilização, 2000.

KUMAR, Krishan. Da sociedade pós-industrial à pós-moderna: novas teorias sobre o mundo contemporâneo. Rio de Janeiro: Jorge Zahar, 1997.

LAHIRE, Bernard. Patrimónios individuais de disposições: para uma sociologia à escala individual. Sociologia: Problemas e Práticas, Lisboa, n. 49, p.11-42, set./dez. 2005. 
LAPA, Tiago. Quadros e trabalhadores no capitalismo flexível: uma abordagem cultural e sócio-cognitiva. CIES e-Working Papers, n. 15, p. 1-33, 2006.

LASH, Scott; URRY, John. The end of organized capitalism. Cambridge: Polity Books, 1987.

LÓPEZ-RUIZ, Osvaldo Javier. 0 ethos dos executivos das transnacionais e 0 espírito do capitalismo. 2004. Tese (Doutorado em Ciências Sociais) - Universidade Estadual de Campinas, Campinas, 2004.

McCLELLAND, David. The achieving society. New York: Van Nostrand, 1961.

MOREIRA, Helena Rita Gonçalves Marinho. Mobilidade e 0 empreendedorismo no ensino superior: 0 caso das ciências sociais. 2009. Tese (Mestrado) - Universidade do Minho, Braga, 2009.

NAIA, Ana Maria P. Importância da formação inicial no empreendedorismo: estudo do percurso empreendedor de licenciados da FMH. 2009. Dissertação (Mestrado) - Universidade de Lisboa, Faculdade de Psicologia e Ciências da Educação, Lisboa, 2009.

NIRAS Consultants; FORA; ECON Pöyry. Survey of entrepreneurship education in higher education in Europe. [s.L.]:European Commission, Oct. 2008.

ROESE, Mauro. Sociologia econômica do empreendedorismo: valores, conhecimento e juventude. CONGRESSO BRASILEIRO DE SOCIOLOGIA, 15., Curitiba, 2011.

SANTOS, Boaventura de Sousa; ALMEIDA FILHO, Naomar de. A universidade no século XXI: para uma universidade nova. Coimbra: Almedina, 2008.

SANTOS, Susana Correia; CAETANO, António; CURRAL, Luís. Atitudes dos estudantes universitários face ao empreendedorismo: como identificar o potencial empreendedor? Revista Portuguesa e Brasileira de Gestão, Lisboa, v. 9, n. 4, p. 2-14, out./dez. 2010.

SENNET, Richard. A corrosão do caráter. Rio de Janeiro: Record, 1999.

SCHUMPETER, Joseph Alois. Teoria do desenvolvimento econômico. Rio de Janeiro: Fundo de Cultura, 1961.

SOUZA, Jessé. Os batalhadores brasileiros: nova classe média ou nova classe trabalhadora? Belo Horizonte: UFMG, 2010.

STEL, André van; CARREE, Martin; THURIK, Roy. The effect of entrepreneurial activity on national economic growth. Small Business Economics, v. 24, n. 3, p. 311-321, 2005.

UNIVERSIDADE DE LISBOA. Empregabilidade e empreendedorismo na Universidade de Lisboa. Lisboa: UL, 2011.

Recebido em: 29.01.2014

Aprovado em: 18.03.2014

Rachel de Castro Almeida é professora da Pontifícia Universidade Católica de Minas Gerais. Foi bolsista de pós-doutorado Capes (processo 4035-11/9), projeto "Ensino superior e inserção profissional: uma incursão pelas trajetórias e disposições de jovens empreendedores" e pesquisadora do projeto "Percursos de inserção dos licenciados: relações objectivas e subjectivas com o trabalho".

Miguel Chaves é professor da Faculdade de Ciências Sociais e Humanas - Universidade Nova de Lisboa, pesquisador do Centro de Estudos de Sociologia da Universidade Nova de Lisboa (CESNOVA), e coordenador do projeto "Percursos de inserção dos licenciados: relações objectivas e subjectivas com o trabalho", (PTDC/CS-SOC/104744/2008), financiado pela Fundação para a Ciência e Tecnologia do Ministério da Ciência, Tecnologia e Ensino Superior. 